\title{
Assessment of Meteorological Drought in Korea under Climate Change
}

\author{
Jaewon Kwak, ${ }^{1}$ Soojun Kim, ${ }^{2}$ Jaewon Jung, ${ }^{3}$ Vijay P. Singh, \\ Dong Ryul Lee, ${ }^{5}$ and Hung Soo Kim ${ }^{6}$ \\ ${ }^{1}$ Forecast and Control Division, Nakdong River Flood Control Office, Busan 49300, Republic of Korea
${ }^{2}$ Columbia Water Center, Earth Institute, Columbia University, New York, NY 10027, USA
${ }^{3}$ Department of Safety and Environment Research, Seoul Institute, Seoul 06756, Republic of Korea
${ }^{4}$ Department of Biological \& Agricultural Engineering, Texas A\&M University, TX 77843, USA
${ }^{5}$ Water Resources Research Division, Korea Institute of Civil Engineering and Building Technology, Goyang 10223, Republic of Korea
${ }^{6}$ Department of Civil Engineering, INHA University, Incheon 22212, Republic of Korea
}

Correspondence should be addressed to Soojun Kim; soojun78@gmail.com

Received 22 June 2016; Accepted 17 October 2016

Academic Editor: Guillermo Baigorria

Copyright (C) 2016 Jaewon Kwak et al. This is an open access article distributed under the Creative Commons Attribution License, which permits unrestricted use, distribution, and reproduction in any medium, provided the original work is properly cited.

Drought has become one of the most important elements for water resources planning and management in Korea. The objective of this study is to estimate the spatial distribution of drought and change in the drought characteristics over time due to climate change. For the spatial characterization of drought, the standardized precipitation index (SPI) is calculated from the 45 observatories in Korea and the spatial distribution is also estimated based on the joint probability analysis using the copula method. To analyze the effect of climate change, spatial distribution of drought in the future is analyzed using the SPI time series calculated from Representative Concentration Pathways (RCPs) scenarios and HADGEM3-RA regional climate model. The results show that the Youngsan River and the northwest of Nakdong River basins in Korea have nearly doubled drought amount compared to the present and are most vulnerable to drought in near future (2016 to 2039 years).

\section{Introduction}

Drought is a major natural disaster and, among all natural disasters, it causes the greatest damage [1]. The annual economic damage due to droughts is estimated to be approximately $\$ 7$ billion globally $[2,3]$. Unquestionably, it causes considerable environmental, socioeconomic, and agricultural strain [4-7]. Therefore, the estimation of the severity, spatial extent, and frequency of droughts is one of the key elements for water resources planning and management.

Since Munger [8] suggested the basic concepts for the quantitative analysis of drought, there are many studies on the quantitative estimation of drought and these can be classified into several categories: index, stochastic, statistical, and so forth. The index approach uses drought index, such as the standardized precipitation index (hereafter referred to as
"SPI") based on the amount of precipitation [9-11], Palmer Drought Severity Index (PDSI) which takes account of the temperature and physical water balance $[12,13]$, Crop Moisture Index (CMI) that evaluates the short-term moisture conditions [14], surface water supply index (SWSI) which monitors abnormalities in surface water supply sources [15], and Vegetation Condition Index (VCI) based on satellite high resolution radiometer data [16], as the quantitative estimator for droughts. Also, there are many studies that suggested various drought indices, including the Effective Precipitation (EP) [17], Soil Moisture Deficit Index (SMDI) [18], Standardized Runoff Index (SRI) [19], Normalized Difference Water Index (NDWI) [20], Drought Monitor (DM) [21], or employed deterministic models [22]. The stochastic approach employs a stochastic model, such as ARIMA [23], SARIMA [24, 25], or Markov chain [26], to simulate the drought characteristics. 

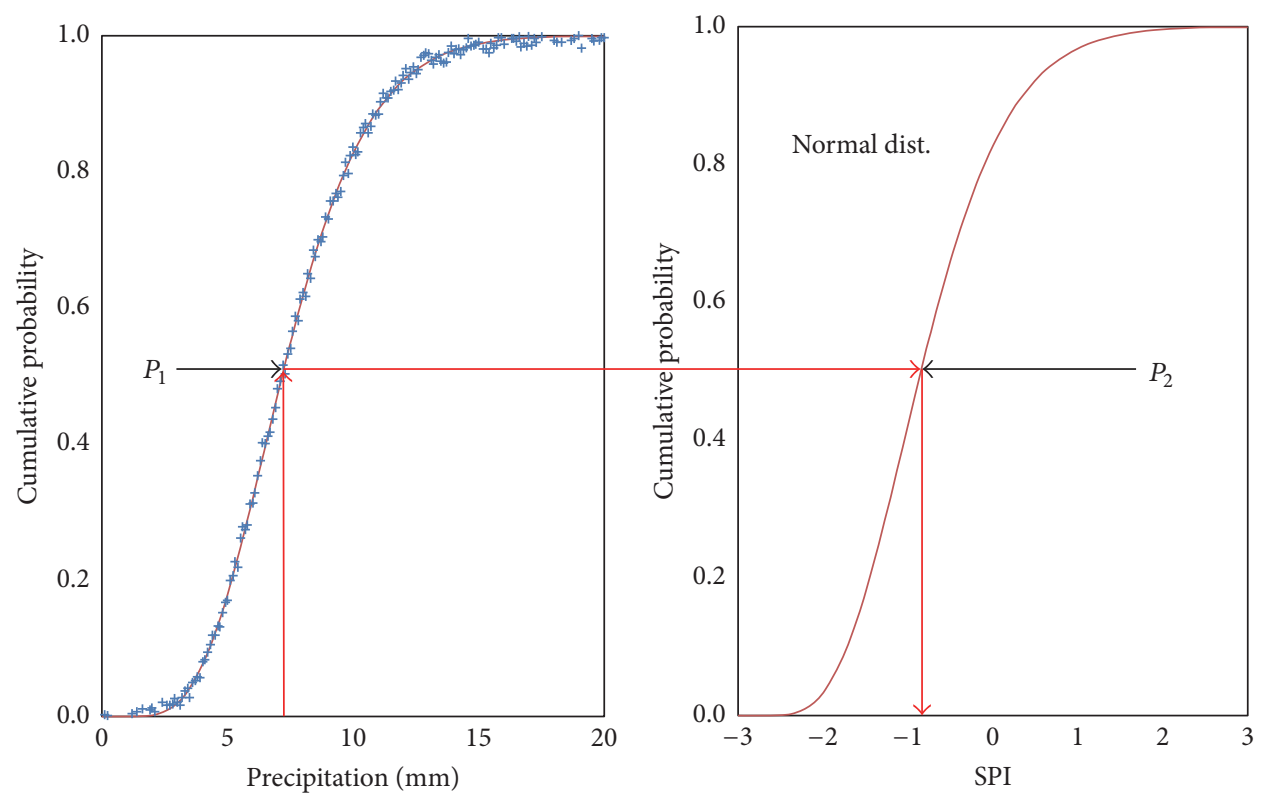

FIGURE 1: Estimation of SPI [9].

In a similar vein, the statistical approach employs various statistical techniques to estimate the drought characteristics, and these techniques can also be divided into statistical modeling, probabilistic distribution, and so forth. Various statistical models have been used for the simulation for drought, such as Artificial Neural Networks [27, 28], regression or linear models [10, 29], principal component regression [30], and spectrum analysis [31]. Some studies consider drought as a probabilistic event, based on the various drought characteristics, such as the drought frequency, persistence characteristic, average severity, and maximum severity [32-35]. Since Shiau et al. $[36,37]$ calculated the joint probability distribution using the copula function combining multiple marginal distributions, the copula function has come to the forefront as an effective tool for multivariate frequency analysis, as it can take account of drought variables that are mutually related [38], and is now being widely utilized [39-44]. In addition, to study the impact of climate change on the drought behavior, Burke et al. [45] used the HadCM3 model to analyze PDSI shifts up to 2100 and Mpelasoka et al. [46] used the climate data from a Global Climate Model (GCM) to calculate the SPI and PDSI and compared them with each other. Also, the regional climate model ( $\mathrm{RCM}$ ) has been used to consider the effect of climate change on the drought variability [47], and some studies have used a GCM model to investigate the frequency of occurrence of PDSI [48]. In particular, many studies on drought and climate change have been performed recently in the East Asia region including Korea, China, and Japan, which are actually affected by climate change $[49,50]$. Nam et al. [51] indicated that the drought in South Korea will significantly increase, and Kim et al. [52] show potential drought areas would shift from the south toward the east and central parts of the country. Similar studies have been performed for China [53-56], India [57], and so on. However, in the perspective of water resources managements, the change of drought amount compared with the present situation because it is closely related to policy and planning, but most of the studies performed drought characteristic analysis based on their own period of the GCM data [58-65].

Therefore, this research focuses on the change in the drought amount and severity through the past to the future period due to climate change. To that end, future rainfall time series were drawn from RCP scenarios and CMIP5 climate model, which were newly suggested by the IPCC's 5th report [66] at the 45 observatories of the Korea Meteorological Administration to define drought. Using the copula method, the drought severity was defined according to the return period. Then, the spatial and temporal changes in the drought due to climate change in near (2016 to 2039), middle (2040 to 2069), and far future (2070 to 2100) were analyzed and compared based on the present drought.

\section{Methodologies}

2.1. SPI. There are different views on the definition of drought. Meteorologically speaking, drought is defined as an event caused by a lack of precipitation, and it has various environmental, societal, and economic impacts. There are many definitions for drought, such as the duration, severity, frequency, and interarrival time, which were developed. Among them, the drought index is a method that is widely used to define drought, because it simplifies the quantitative characteristics.

The SPI, suggested by Mckee et al. [9], is an example of a broadly used drought index. The SPI applies a probability distribution to a cumulative precipitation series and then applies a standard normal distribution for the calculations (see Figure 1). Strictly speaking, the SPI does not have a 
TABLE 1: Drought intensity with SPI [9].

\begin{tabular}{lc}
\hline SPI values & Drought category \\
\hline 0 to -0.99 & Mild drought \\
-1.00 to -1.49 & Moderate drought \\
-1.50 to -2.00 & Severe drought \\
$<-2.00$ & Extreme drought \\
\hline
\end{tabular}

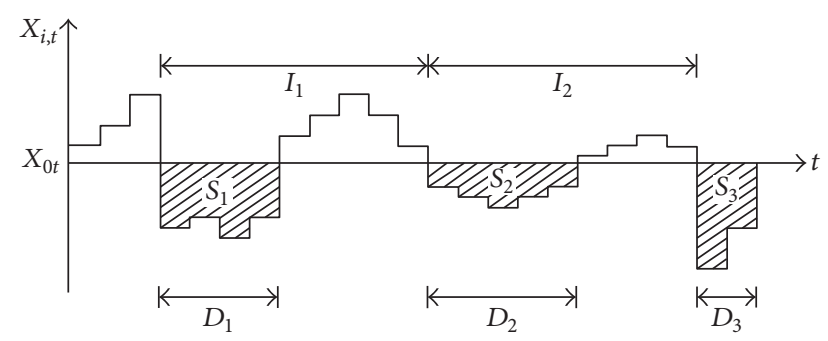

$D_{i}$ : drought duration

$S_{i}$ : drought severity

$I_{i}$ : drought interarrival time

FIGURE 2: Drought characteristics estimated using the run theory [88].

specific threshold, but a drought is regarded as drought when the SPI is -1.0 or lower (Table 1 ).

2.2. Run Theory. The run theory was suggested by Yevjevich [32] to define drought and calculate its characteristics, such as its duration, severity, frequency, and interarrival times. As shown in Figure 2, drought is defined as a time period for which a hydrometeorological variable $x_{t}$ is lower than a truncation level $x_{0}$. The truncation level can be a constant or a time-related function. The values of a precipitation time series which fall below the truncation level define a drought and the period for which they consecutively fall below this level defines the drought duration comprising periods $\left(D_{1}, D_{2}, \ldots\right)$. The cumulative shortage during each period defines the drought severity comprising $\left(S_{1}, S_{2}, \ldots\right)$. The time gap between the initial points of two consecutive droughts defines the drought interarrival time comprising $\left(I_{1}, I_{2}, \ldots\right)$.

The run theory is convenient to apply and can also be applied to other hydrometeorological time series. This study considers the SPI as a continuous hydrometeorological time series and then, by applying the run theory, the drought duration, severity, and interarrival time are obtained. Since drought events are based on the truncation level, the selection of a proper level is important. In this study, a value of -1.00 was selected as the truncation level, because it has been generally adopted as the critical value to analyze droughts using statistical techniques [25, 67-71].

2.3. Copula Function. To derive a joint probability distribution of two or more variables that are dependent on each other, the most viable method is the copula method. If $F\left(x_{1}, \ldots, x_{n}\right)$ is an $n$-dimension distribution function with marginal distributions of $F_{1}\left(x_{1}\right), \ldots, F_{n}\left(x_{n}\right)$, then there exists a copula function $C$ which satisfies $F\left(x_{1}, \ldots, x_{n}\right)=C\left(F_{1}\left(x_{1}\right), \ldots, F_{n}\left(x_{n}\right)\right)$. If $F_{1}\left(x_{1}\right), \ldots, F_{n}\left(x_{n}\right)$ are continuous, then the copula function can be represented as $C\left(u_{1}, \ldots, u_{n}\right)=F\left(F_{1}^{-1}\left(u_{1}\right), \ldots, F_{n}^{-1}\left(u_{n}\right)\right)$. Here $x_{i}, i=$ $1,2, \ldots, n$, are random variables with marginal distribution functions expressed as $F_{i}\left(x_{i}\right), i=1,2, \ldots, n$ If the above function is partially differentiated with respect to $x_{1}, \ldots, x_{n}$, function (1) can be obtained:

$$
\begin{aligned}
& f\left(x_{1}, \ldots, x_{n}\right)=C\left(F_{1}\left(x_{1}\right), \ldots, F_{n}\left(x_{n}\right)\right) \prod_{i=1}^{n} f_{i}\left(x_{i}\right), \\
& C\left(u_{1}, \ldots, u_{n}\right)=\frac{f\left(F_{1}^{-1}\left(u_{1}\right), \ldots, F_{1}^{-1}\left(u_{n}\right)\right)}{\prod_{i=1}^{n} f_{i}\left(x_{i}\right)} .
\end{aligned}
$$

Thus, the joint probability distribution can be obtained from the marginal probability density functions and the copula function. There are many copula families but, in this study, the Archimedean copula family was selected, because of its flexibility and simplicity of use [36-38, 41-43] and was applied to investigate droughts. From the Archimedean copula family, the Clayton, Gumbel, and Frank copulas were employed and their functions are given in Nelsen [72] and Table 2.

To determine the copula parameter, the canonical maximum likelihood method (CML) was used [73]. The CML method uses a marginal transformation to transform each data piece to a uniform distribution and, then, using the parameter of each distribution function, the copula parameter is estimated.

\section{Drought Return Period Using SPI}

3.1. Drought Definition with SPI. This study calculated the SPI indices for the 45 observatories of the Korea Meteorological Administration (hereafter referred to as "KMA") to assess their potential effect on water resources management (see Figure 3). To do so, the daily precipitation data between 1974 and 2014 were cumulated by month. Then, an appropriate probability distribution was applied to the time series of monthly rainfall for each duration period. To calculate the SPI, a 6-month duration period was selected, since it is the most suitable duration for analyzing the long-term meteorological drought characteristics [74]. For the SPI, there are considerable differences between distributions, so the Pearson Type III distribution, suggested by Guttman [31] through suitability testing, was selected to calculate the SPI [75].

The truncation level must be set to define drought from the SPIs of the 45 climate observatories. Since the SPI recognizes -1.0 or less as a moderate drought, this value was regarded as the truncation level to define drought events for each observatory (see Figure 4).

For the Seoul Climate Observatory, the leading observation facility in Korea, the drought events are shown in Figure 5.

3.2. Bivariate Analysis of Drought. To estimate the joint probability distribution using the copula method, the marginal 
TABLE 2: Bivariate Archimedean copula family; $C$ is the copula function, $t$ denotes the drought event, $\alpha$ is the copula parameter, and $F_{1}$ and $F_{2}$ denote the marginal distributions [72].

\begin{tabular}{lccc}
\hline $\begin{array}{l}\text { Copula } \\
\text { family }\end{array}$ & Copula func., $C\left(F_{1}\left(x_{1}\right), F_{2}\left(x_{2}\right)\right)$ & Generator func., $\psi_{\alpha}(t)$ & $\begin{array}{c}\text { Parameter } \\
(\alpha)\end{array}$ \\
\hline Clayton & $\left(\max \left\{F_{1}\left(x_{1}\right)^{-1}+F_{2}\left(x_{2}\right)^{-1}-1 ; 0\right\}\right)^{-1 / \alpha}$ & $\frac{1}{\alpha}\left(t^{-\alpha}-1\right)$ & $\alpha \in[-1, \infty]$ \\
Frank & $\frac{-1}{\alpha} \log \left(1+\frac{\left(\exp \left(-\alpha F_{1}\left(x_{1}\right)\right)-1\right)\left(\exp \left(-\alpha F_{2}\left(x_{2}\right)\right)-1\right)}{\exp (-\alpha)-1}\right)$ & $-\log \left(\frac{\exp (-\alpha t)-1}{\exp (-\alpha)-1}\right)$ & $-\log (t)^{\alpha}$ \\
Gumbel & $\exp \left(-\left(\left(-\log \left(F_{1}\left(x_{1}\right)\right)\right)^{\alpha}+\left(-\log \left(F_{2}\left(x_{2}\right)\right)\right)^{\alpha}\right)^{1 / \alpha}\right)$ & $\alpha \in[1, \infty]$ \\
\hline
\end{tabular}

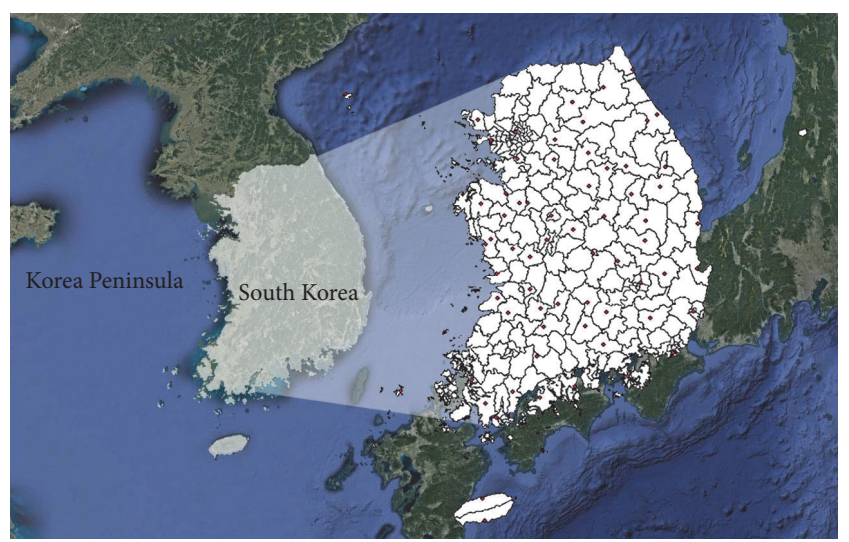

FIGURE 3: Study area and the location of 45 observatories of KMA; red dot indicated the location of KMA observatories.

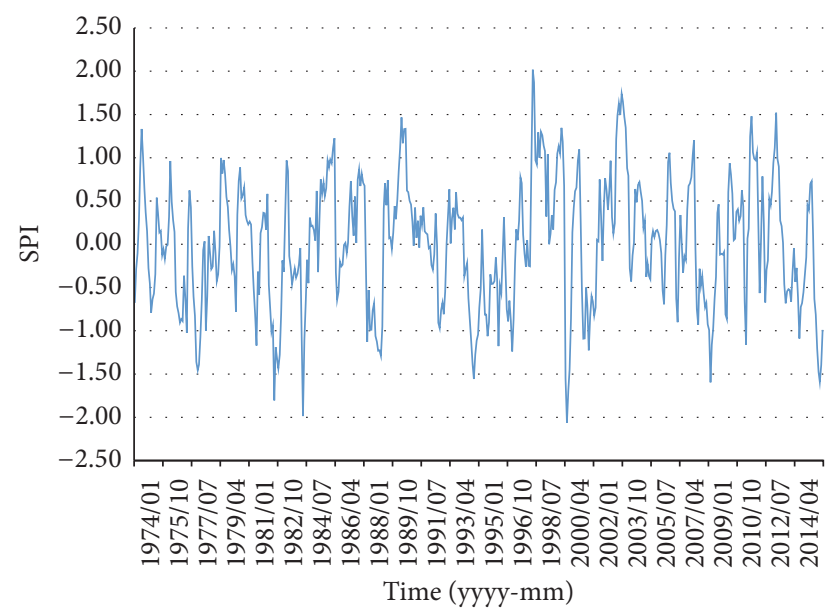

Figure 4: Mean SPI time series of South Korea (1974-2015).

probability distributions must be simulated beforehand. Each drought variable of the SPI time series for the 45 observatories was analyzed to determine the proper distribution type. The joint probability distribution of two drought variables was derived using the proper copula function for each observatory. For the selection of the proper copula value, the minimum quadratic distance $\left(L^{2}\right)$ between the empirical and theoretical values of the $K$ criterion, which describe the most appropriate copula [76], was employed. The parameters of the

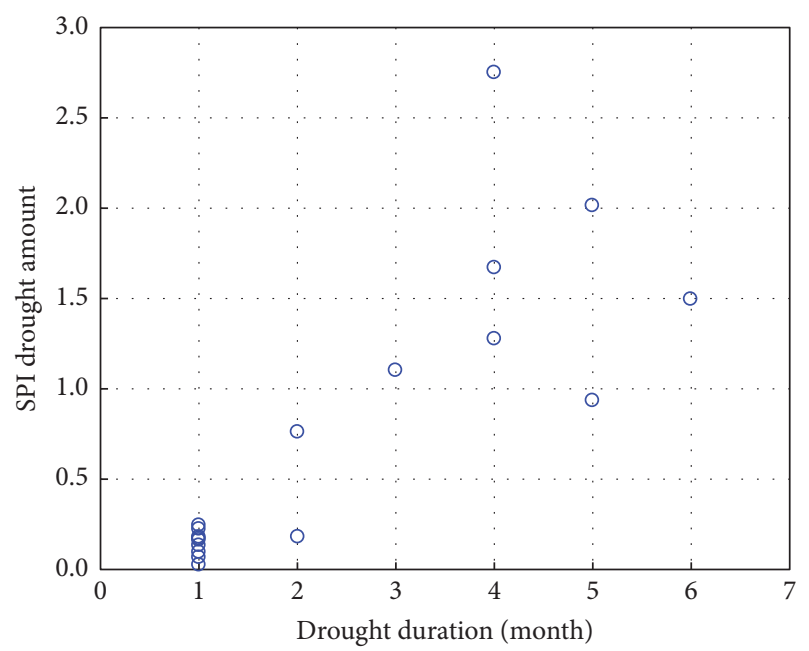

○ Monthly SPI

FIgURE 5: Drought events of Seoul observatory (1974-2015).

Archimedean family copulas (Frank, Clayton, and Gumbel) were estimated by the method of moments according to their relationship with Kendall's tau [77], which was found to be adequate for estimating the parameters for small sample sizes [76]. In calculation of joint probability based on the copula function, there are two cases: both duration and severity exceeding the limit $(D>d$ and $S>s)$, or probability either one would $(D>d$ or $S>s)$ [36]. This study assumes that an elongated duration implies an increase in the overall severity and, according to a previous study [78], the joint probabilities of duration and severity are assumed to exhibit similar spatial distribution characteristics. Therefore, for convenience of analysis, the spatial distribution was generated using the duration. In this manner, the return period was defined based on the drought duration and severity. Also, the drought frequency was quantified using the return period. Figure 6 represents the return period of drought according to the SPI and the spatial distribution of drought in accordance with duration. For example, if the return period of drought was 30 years with a duration of 1 month, then the SPI of the Guem River basin was -1.75 according to Figure 6(b) and the severity of probable drought can be drawn from this.

The spatial distribution of drought, based on the SPI, shows that droughts that have the same return period tend 


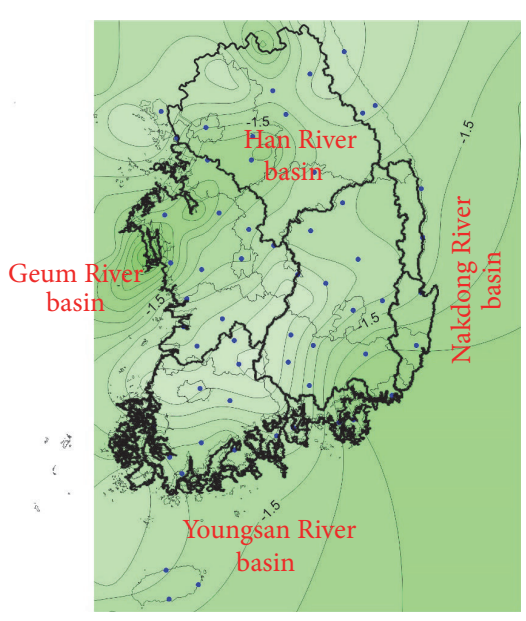

(a)

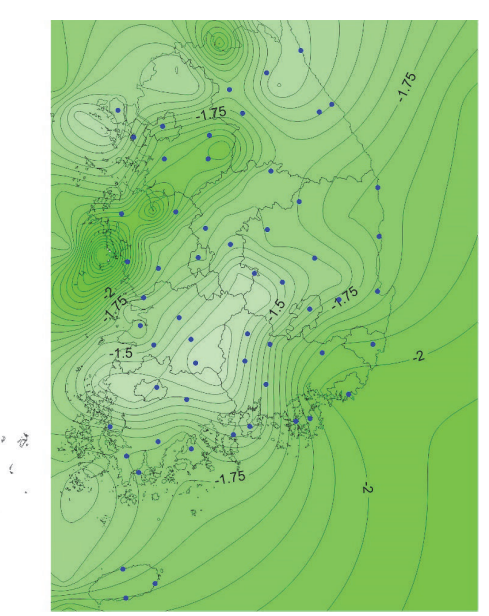

(c)

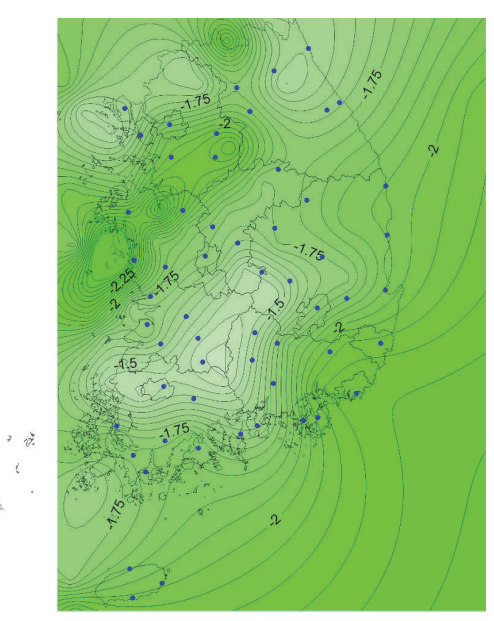

(e)

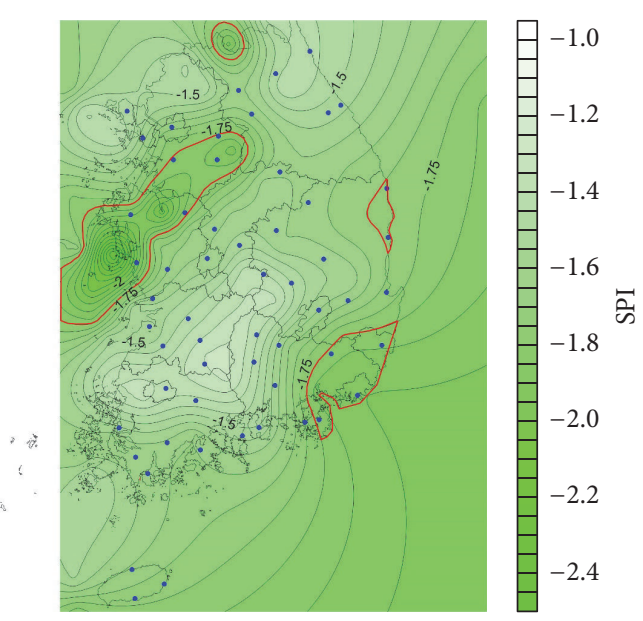

(b)

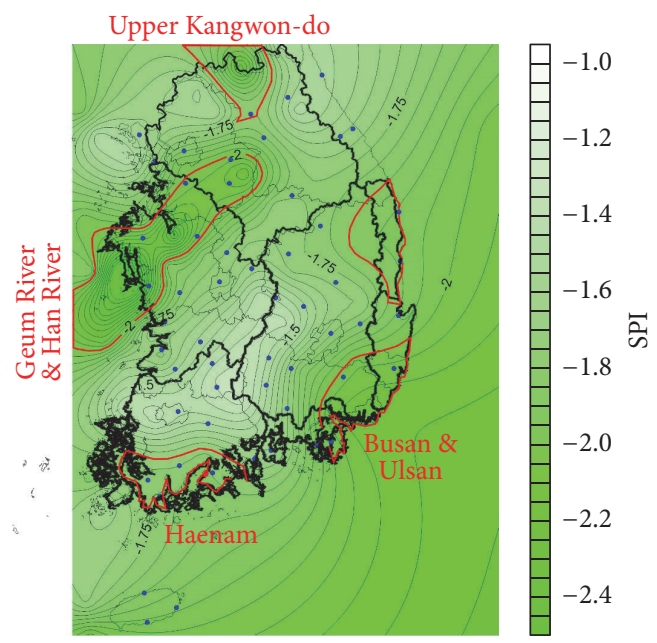

(d)

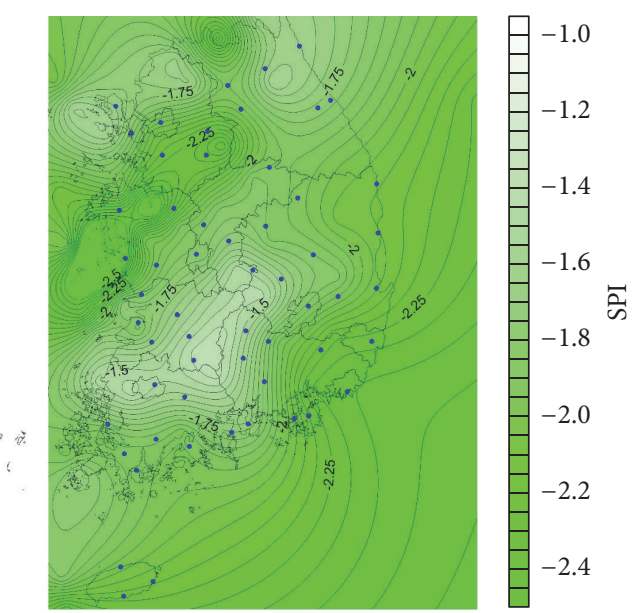

(f)

FigURE 6: Drought spatial distribution by SPI (1-month duration, 1967-2015); (a) $10 \mathrm{yr}$ return period; (b) $30 \mathrm{yr}$; (c) $50 \mathrm{yr}$; (d) $80 \mathrm{yr}$; (e) $100 \mathrm{yr}$; (f) $200 \mathrm{yr}$. 
TABLE 3: RCP scenario description [84].

\begin{tabular}{|c|c|c|c|}
\hline Scenarios & Description & $\begin{array}{l}\text { CO density } \\
(\mathrm{ppm})\end{array}$ & $\begin{array}{l}\text { Global warming } \\
\text { until } 2100 \text { (mean } \\
\text { and likely range) }\end{array}$ \\
\hline RCP 2.6 & $\begin{array}{l}\text { Peak in radiative forcing at } \sim 3 \mathrm{~W} / \mathrm{m} \text { before year } \\
\qquad 2100 \text { and then decline }\end{array}$ & 490 & $1.0(0.3 \sim 1.7)^{\circ} \mathrm{C}$ \\
\hline RCP 4.5 & $\begin{array}{l}\text { Stabilization without overshoot pathway to } \\
\sim 4.5 \mathrm{~W} / \mathrm{m} \text { at stabilization after year } 2100\end{array}$ & 650 & $1.8(1.1 \sim 2.6)^{\circ} \mathrm{C}$ \\
\hline RCP 6.0 & $\begin{array}{l}\text { Stabilization without overshoot pathway to } \\
\sim 6 \mathrm{~W} / \mathrm{m} \text { at stabilization after year } 2100\end{array}$ & 850 & $2.2(1.4 \sim 3.1)^{\circ} \mathrm{C}$ \\
\hline RCP 8.5 & $\begin{array}{l}\text { Rising radiative forcing pathway leading to } \\
\qquad 8.5 \mathrm{~W} / \mathrm{m} \text { by year } 2100\end{array}$ & 1370 & $3.7(2.6 \sim 4.8){ }^{\circ} \mathrm{C}$ \\
\hline
\end{tabular}

to have a higher severity around the Geum River basin and the upper part of Kangwon-do province, Busan, and Haenam (see Figure 6(d)). Even though there are differences in their duration, the overall spatial distributions are similar. This means that when a drought with the same return period occurs, these regions are vulnerable.

\subsection{Future Rainfall Projection and Drought Variability under Climate Change}

3.3.1. Future Rainfall Series. To obtain future meteorological variables, a climate change scenario and a climate model are essential. This study employed CMIP5, because it includes more global circulation models [79] with generally higher spatial resolution, making it possible to address a wider variety of scientific questions [80,81]. Also, climate projections vary, based on the external forcing factor, greenhouse gas emission scenarios, and numerical models [82]. The Intergovernmental Panel on Climate Change (IPCC) determined the emission density of greenhouse gases, based on human impact on the atmosphere in the form of RCP scenarios [83]. The climate change scenarios in CMIP5 describe four possible climatic futures (RCP 2.6, 4.5, 6.0, and 8.5), all of which are considered possible, depending on how much greenhouse gases will be emitted [84] and the degree of reduction of carbon dioxide (Table 3 ). Hence, the selection of these scenarios is one of the most important factors in the assessment of climate change.

The RCP 2.6 scenario assumes that the greenhouse gas emissions reach a peak between 2010 and 2020 and then decline substantially, while in RCP 4.5 the emissions reach a peak around 2040 and then decline, and in RCP 6.0 the emissions peak around 2080 and then decline. However, in the RCP 8.5 scenario, greenhouse gas emissions continue to rise throughout the 21st century [84]. The KMA projected future climate phenomena using the HadGEM2-AO model with a 1-degree resolution and downscaled its results, based on HadGEM3-RA of the Hadley Centre of the British Meteorological Office [85]. The KMA RCM model simulates the entire East Asia region, including the Korea Peninsula, by dividing it into a $12.5 \times 12.5 \mathrm{~km}$ grid and providing monthly and daily climate phenomena until 2100 [86]. The RCP 4.5 scenario was employed and the monthly projected future precipitation $(\mathrm{mm})$ was obtained until 2100.

3.3.2. Future Drought Variability. To analyze the changes in the short- and long-term droughts due to climate change in the future, 4 projection periods were designated including the present:

Case 1: Jan. 1974-Dec. 2015 (observation period),

Case 2: Jan. 2016-Dec. 2039 (projection period 1),

Case 3: Jan. 2040-Dec. 2069 (projection period 2),

Case 4: Jan. 2070-Dec. 2100 (projection period 3),

To assess the influence of climate change on drought in accordance with the case period, the future precipitation was calculated using the RCP 4.5 scenario and KMA RCM model and the SPI time series was simulated. Drought events were defined using the simulated future SPI time series. Then, by applying the copula method, the joint probability index of drought and SPI for each period were calculated and their variability was analyzed. The calculated SPI was represented as the relative rate of change in the SPI of Case 1. From the perspective of water resources management, the severity of future drought due to climate change would be the main item of interest. Thus, after representing it as the rate of change of SPI in comparison to Case 1 , the substantive severity trend due to climate change in the future was investigated. To accomplish this, the SPI values for drought with frequencies of $5,10,30,50,80,100,200$, and 500 years were calculated. Then, the SPI values were compared to the SPI values of the same return period for Case 1 and the average rate of change was calculated. To discern the distribution of the rate of change of drought, mitigating drought was represented as a positive rate of change (white) and intensifying drought was represented as a negative rate of change (blue). The range of rate of change was set from $1 / 2$ of mitigation (200\%) to double intensification (-200\%). See Figures 7-9 for reference.

By comparing the rate of change of drought in Figures 7-9 for the drought severity of each return period in Case 1, interesting observations can be made. Increases in the drought severity are observed in the upper part of Kangwon-do and northwest part of the Nakdong River basin and especially in the whole area of the Youngsan River basin (see Figures 7(d), 


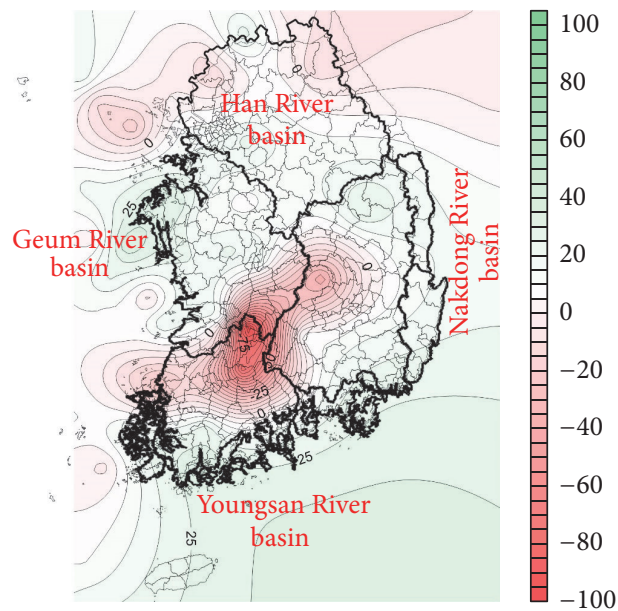

(a)

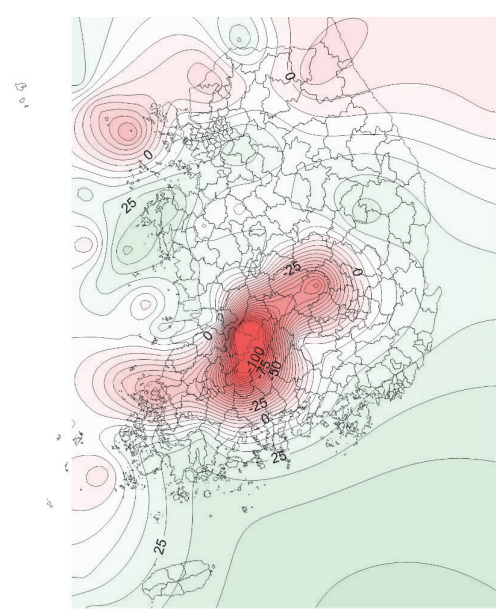

(c)

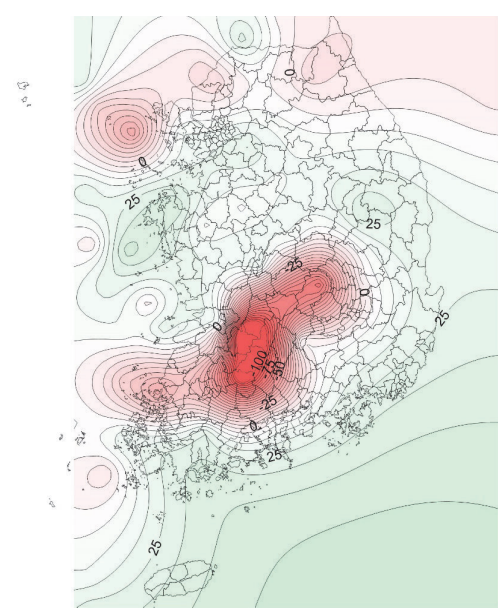

(e)

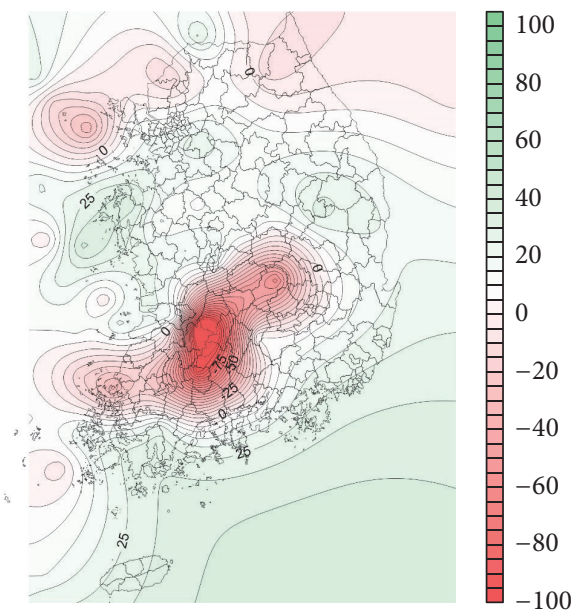

(b)

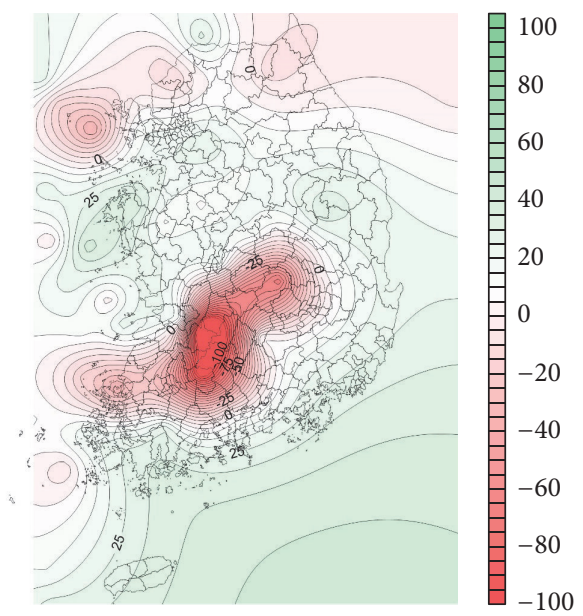

(d)

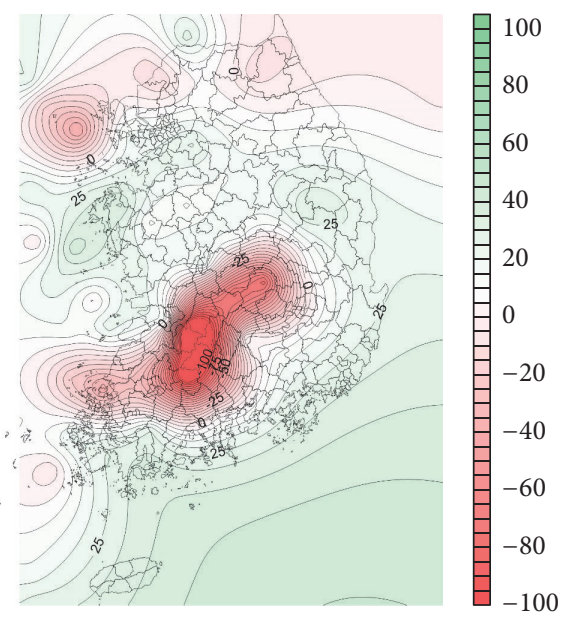

(f)

FIGURE 7: SPI-contrasted drought's rate of change for Case 2 (1-month duration); (a) $10 \mathrm{yr}$ return period; (b) $30 \mathrm{yr}$; (c) $50 \mathrm{yr}$; (d) $80 \mathrm{yr}$; (e) $100 \mathrm{yr}$; (f) $200 \mathrm{yr}$. 


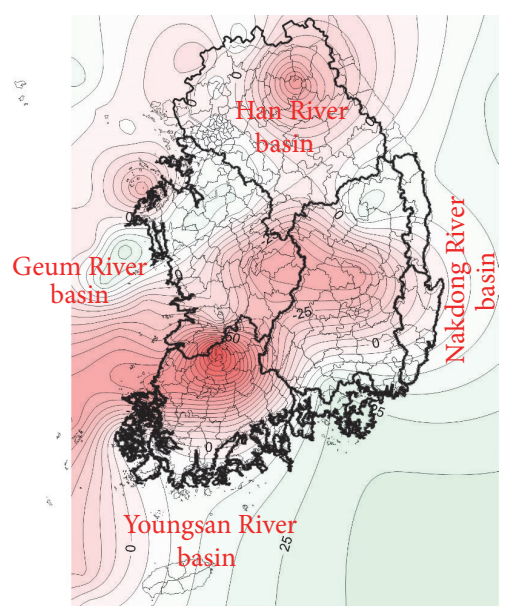

(a)

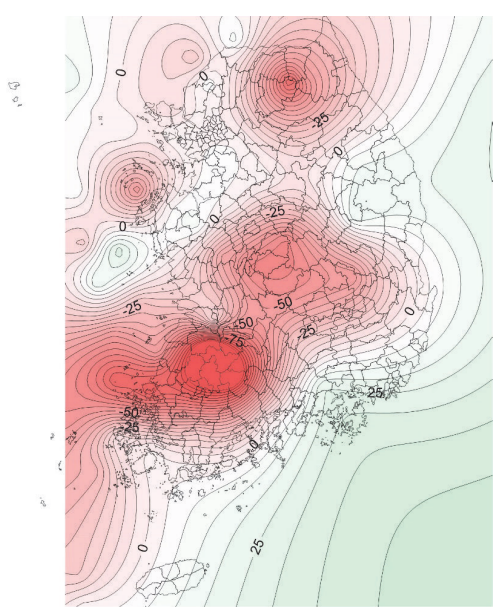

(c)

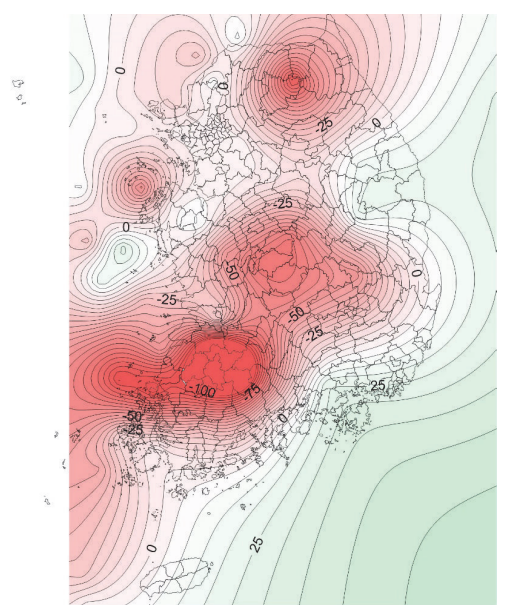

(e)
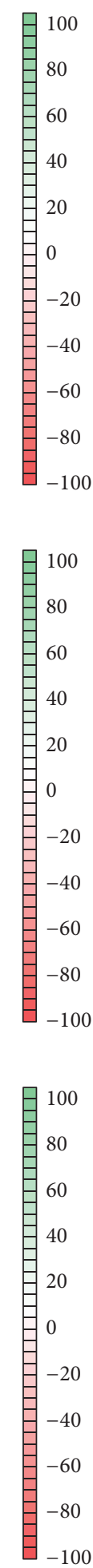

$-100$

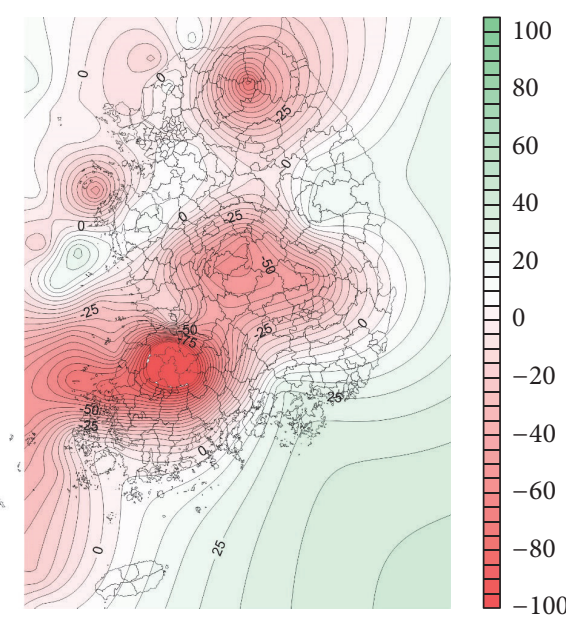

(b)

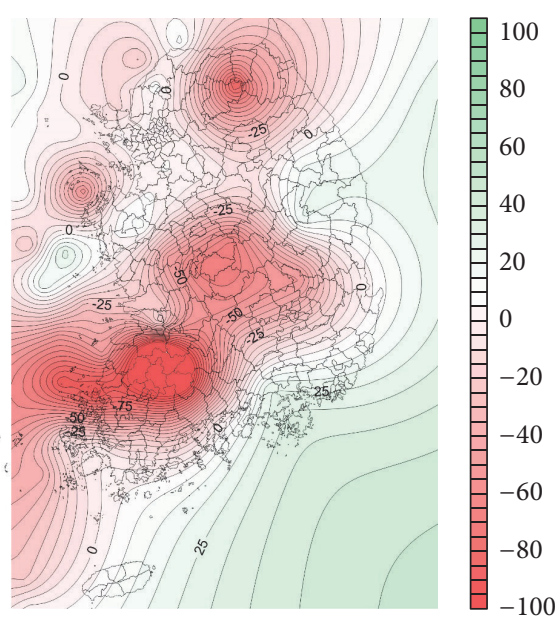

(d)

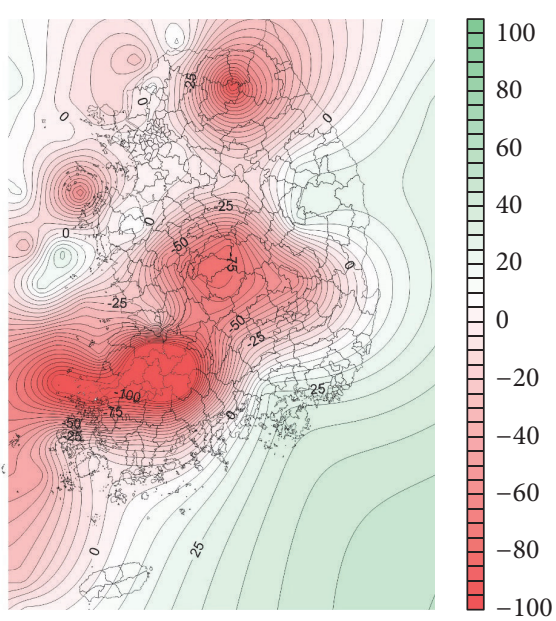

(f)

Figure 8: SPI-contrasted drought's rate of change for Case 3 (1-month duration); (a) $10 \mathrm{yr}$ return period; (b) $30 \mathrm{yr}$; (c) $50 \mathrm{yr}$; (d) $80 \mathrm{yr}$; (e) $100 \mathrm{yr}$; (f) $200 \mathrm{yr}$. 


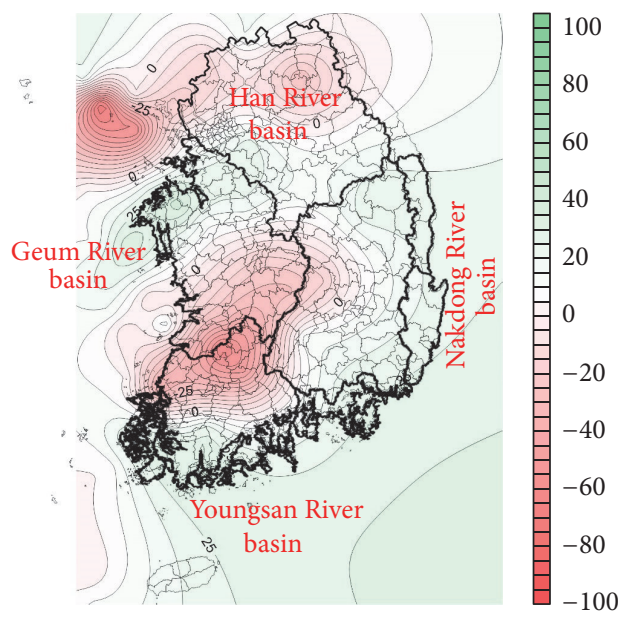

(a)

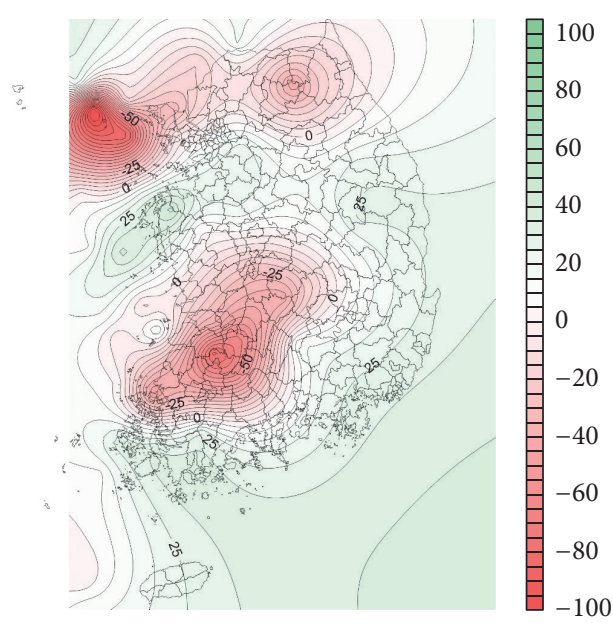

(c)

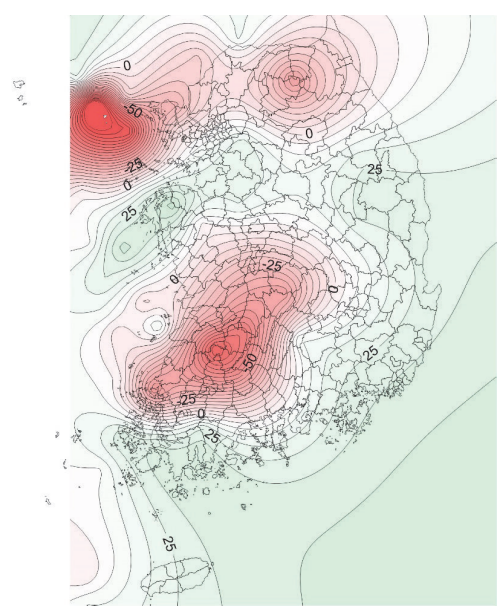

(e)

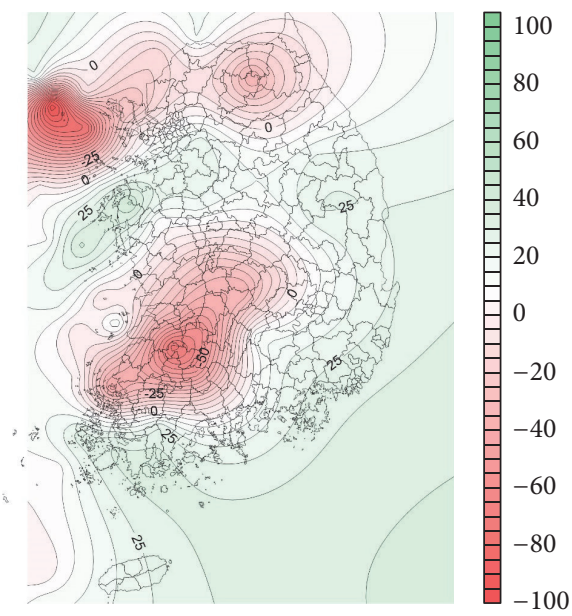

(b)

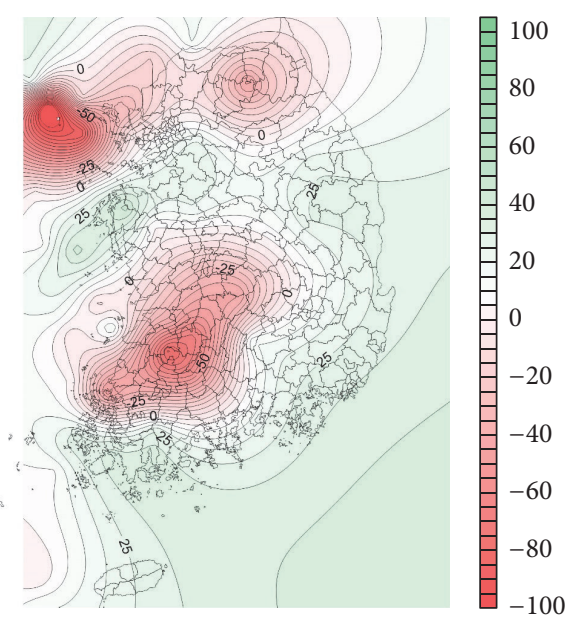

(d)

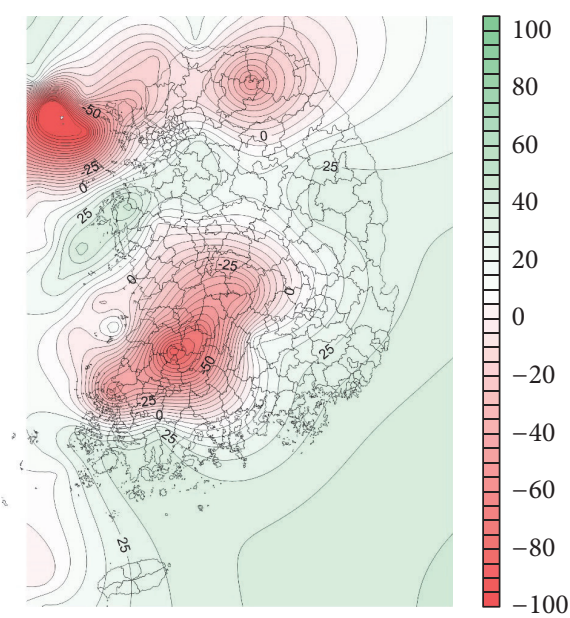

(f)

FIGURE 9: SPI-contrasted drought's rate of change for Case 4 (1-month duration); (a) $10 \mathrm{yr}$ return period; (b) $30 \mathrm{yr}$; (c) $50 \mathrm{yr}$; (d) $80 \mathrm{yr}$; (e) $100 \mathrm{yr}$; (f) $200 \mathrm{yr}$. 
$8(d)$, and $9(d))$. When comparing the drought distribution of Case 1 in Figure 6 to that in the other areas, the areas with low drought severity and with a high increase in drought severity due to climate change generally match (see Figures 7-9). This shows that the severity of drought is increasing in areas which previously had a low drought severity, due to climate change. Thus, it can be concluded that the drought severity of the entire South Korea is on the rise.

The increase in droughts in Haenam, which is located south of the Youngsan River Basin, should be noted. Accordingly, this area shows high severity of drought in the drought severity distribution for Case 1 and also shows a high rate of change in drought severity due to climate change. In the middle of the Youngsan River basin for Case 2, the upstream and downstream parts of the Youngsan River basin in Cases 3 and 4 show a trend of drought intensification (see Figures 7(d), 8(d), and 9(d)). Thus, the Youngsan River basin's drought severity is higher than that of any other area and this shows that the future drought severity will intensify due to climate change. Thus, as time goes on, the overall drought vulnerability of the Youngsan and Nakdong River basins will increase. Also, in the near future (2016-2040), the increase of the drought severity of the Youngsan River and northwest Nakdong River basins will be especially striking with the nearly doubled drought amount compared to the present (see Figure 7). In particular, Youngsan River basin has a small amount of reservoir or dam capacities (totally 1214.5 million $\mathrm{m}^{3}$ ) [87] compared to other basins. So, the Youngsan River basin appears to be especially vulnerable to drought, so establishing an elaborate drought management plan is vital, and a water resources management plan for the increase of drought amount in these areas is highly needed.

\section{Conclusions}

The present research analyzed the changing trend of meteorological drought in Korea due to climate change. Drought was defined by the SPIs collected from the 45 observatories all over Korea. The joint probability distribution and return period of severity and duration, the most important probability variables, were derived using the copula method and the characteristics of drought were studied to determine their spatial distribution over South Korea. To consider the influence of climate change, the future SPI indices were calculated using the RCP 4.5 scenario and KMA RCM. Then, the same methodology was applied to simulate future droughts and the rate of change was compared to the current drought data. From this research, the following conclusions can be drawn:

(1) The drought return period calculated from the SPIs collected from the 45 climate observatories of the KMA shows that parts of the Geum, Nakdong, and Han River basins are vulnerable to drought.

(2) The drought severity of those areas that are currently relatively free from drought will increase in the future due to climate change and the overall influence of drought in South Korea will grow.
(3) Currently, the upstream and downstream parts of the Kuem River basin have higher drought severities than the other areas. Also, the increase in drought severity due to climate change in the Youngsan River basin will be higher than that in other areas. Thus, the Youngsan River basin is more vulnerable to drought on the climate change.

\section{Competing Interests}

The authors declare that there is no conflict of interests regarding the publication of this paper.

\section{Acknowledgments}

This study was conducted with financial support from the Korean Institute of Civil Engineering and Building Technology's Strategic Research Project (Operation of Hydrological Radar and Development of Web and Mobile Warning Platform). Moreover, this study was also supported by a grant (14AWMP-B082564-01) from Advanced Water Management Research Program funded by Ministry of Land, Infrastructure and Transport of Korean Government.

\section{References}

[1] D. A. Wilhite, "Drought as a natural hazard: concepts and definitions," in Drought, A Global Assessment, Routledge, New York, NY, USA, 2000.

[2] Y. Mao, B. Nijssen, and D. P. Lettenmaier, "Is climate change implicated in the 2013-2014 California drought? A hydrologic perspective," Geophysical Research Letters, vol. 42, no. 8, pp. 2805-2813, 2015.

[3] Z. Hao, A. AghaKouchak, N. Nakhjiri, and A. Farahmand, "Global integrated drought monitoring and prediction system," Scientific Data, vol. 1, Article ID 140001, 2014.

[4] J. Saba, M. Moghaddam, K. Ghassemi, and M. R. Nishabouri, "Genetic properties of drought resistance indices," Journal of Agricultural Science and Technology, vol. 3, no. 1, pp. 43-49, 2001.

[5] J. Ashkani, H. Pakniyat, Y. Emam, M. T. Assad, and M. J. Bahrani, "The evaluation and relationships of some physiological traits in spring safflower (Carthamus tinctorius L.) under stress and non-stress water regimes," Journal of Agricultural Science and Technology, vol. 9, no. 4, pp. 267-277, 2007.

[6] N. Ghaderi, A. R. Talai, A. Ebadi, and H. Lessani, "The physiological response of three Iranian grape cultivars to progressive drought stress," Journal of Agricultural Science and Technology, vol. 13, no. 4, pp. 601-610, 2011.

[7] T. L. Kumar, H. Barbosa, K. K. Rao, and E. P. Jothi, "Some studies on the frequency of extreme weather events over India," Journal of Agricultural Science and Technology, vol. 14, no. 6, pp. 13431356, 2012.

[8] T. T. Munger, "Graphic method of representing and comparing drought intensities," Monthly Weather Review, vol. 44, no. 11, pp. 642-643, 1916.

[9] T. B. McKee, N. J. Doesken, and J. Kleist, "Drought monitoring with multiple time scales," in Proceedings of the 9th Conference on Applied Climatology, pp. 233-236, American Meteorological Society, Dallas, Tex, USA, 1985. 
[10] E. E. Moreira, A. A. Paulo, L. S. Pereira, and J. T. Mexia, "Analysis of SPI drought class transitions using loglinear models," Journal of Hydrology, vol. 331, no. 1-2, pp. 349-359, 2006.

[11] S. Michaelides and S. Pashiardis, "Monitoring drought in Cyprus during the 2007-2008 hydrometeorological year by using the standardized precipitation index (SPI)," European Water, vol. 23, no. 24, pp. 123-131, 2008.

[12] C. Palmer Wayne, Meteorological Drought, US Department of Commerce, Weather Bureau, Washington, DC, USA, 1965.

[13] E. Liang, X. Shao, H. Liu, and D. Eckstein, “Tree-ring based PDSI reconstruction since AD 1842 in the Ortindag Sand Land, east Inner Mongolia," Chinese Science Bulletin, vol. 52, no. 19, pp. 2715-2721, 2007.

[14] W. C. Palmer, "Keeping track of crop moisture conditions, nationwide: the new crop moisture index," Weatherwise, vol. 21, no. 4, pp. 156-161, 1968.

[15] D. C. Garen, "Revised surface-water supply index for Western United States," Journal of Water Resources Planning and Management, vol. 119, no. 4, pp. 437-454, 1993.

[16] F. N. Kogan, "Droughts of the late 1980s in the United States as derived from NOAA polar-orbiting satellite data," BulletinAmerican Meteorological Society, vol. 76, no. 5, pp. 655-668, 1995.

[17] H.-R. Byun and D. A. Wilhite, "Objective quantification of drought severity and duration," Journal of Climate, vol. 12, no. 9, pp. 2747-2756, 1999.

[18] B. Narasimhan and R. Srinivasan, "Development and evaluation of Soil Moisture Deficit Index (SMDI) and Evapotranspiration Deficit Index (ETDI) for agricultural drought monitoring," Agricultural and Forest Meteorology, vol. 133, no. 1-4, pp. 69-88, 2005.

[19] S. Shukla and A. W. Wood, "Use of a standardized runoff index for characterizing hydrologic drought," Geophysical Research Letters, vol. 35, no. 2, 2008.

[20] X. Xiao, S. Boles, J. Liu, D. Zhuang, and M. Liu, "Characterization of forest types in Northeastern China, using multitemporal SPOT-4 VEGETATION sensor data," Remote Sensing of Environment, vol. 82, no. 2-3, pp. 335-348, 2002.

[21] M. Svoboda, D. LeComte, M. Hayes et al., "The drought monitor," Bulletin of the American Meteorological Society, vol. 83, no. 8, pp. 1181-1190, 2002.

[22] J. Rhee, J. Im, and G. J. Carbone, "Monitoring agricultural drought for arid and humid regions using multi-sensor remote sensing data," Remote Sensing of Environment, vol. 114, no. 12, pp. 2875-2887, 2010.

[23] P. Han, P. X. Wang, S. Y. Zhang, and D. H. Zhu, "Drought forecasting based on the remote sensing data using ARIMA models," Mathematical and Computer Modelling, vol. 51, no. 1112, pp. 1398-1403, 2010.

[24] A. K. Mishra and V. R. Desai, "Drought forecasting using stochastic models," Stochastic Environmental Research and Risk Assessment, vol. 19, no. 5, pp. 326-339, 2005.

[25] R. Modarres, "Streamflow drought time series forecasting," Stochastic Environmental Research and Risk Assessment, vol. 21, no. 3, pp. 223-233, 2007.

[26] A. Cancelliere and J. D. Salas, "Drought length properties for periodic-stochastic hydrologic data," Water Resources Research, vol. 40, no. 2, 2004.

[27] A. K. Mishra, V. R. Desai, and V. P. Singh, "Drought forecasting using a hybrid stochastic and neural network model," Journal of Hydrologic Engineering, vol. 12, no. 6, pp. 626-638, 2007.
[28] A. Belayneh, J. Adamowski, B. Khalil, and B. Ozga-Zielinski, "Long-term SPI drought forecasting in the Awash River Basin in Ethiopia using wavelet neural network and wavelet support vector regression models," Journal of Hydrology, vol. 508, pp. 418-429, 2014.

[29] R. Chifurira and D. Chikobvu, "A probit regression model approach for predicting drought probabilities in Zimbabwe using the Southern Oscillation Index," Mediterranean Journal of Social Sciences, vol. 5, no. 20, pp. 656-663, 2014.

[30] K. Fang, N. Davi, X. Gou et al., "Spatial drought reconstructions for central High Asia based on tree rings," Climate Dynamics, vol. 35, no. 6, pp. 941-951, 2010.

[31] N. B. Guttman, "Accepting the standardized precipitation index: a calculation algorithm," Journal of the American Water Resources Association, vol. 35, no. 2, pp. 311-322, 1999.

[32] V. Yevjevich, An Objective Approach to Definitions and Investigations of Continental Hydrologic Drought, Colorado State University, Fort Collins, Colo, USA, 1967.

[33] J. A. Dracup, K. S. Lee, and E. G. Paulson Jr., "On the statistical characteristics of drought events," Water Resources Research, vol. 16, no. 2, pp. 289-296, 1980.

[34] H. A. Loaiciga and R. B. Leipnik, "Stochastic renewal model of low-flow streamflow sequences," Stochastic Hydrology and Hydraulics, vol. 10, no. 1, pp. 65-85, 1996.

[35] T. C. Sharma, "Estimation of drought severity on independent and dependent hydrologic series," Water Resources Management, vol. 11, no. 1, pp. 35-49, 1997.

[36] J. T. Shiau, "Fitting drought duration and severity with twodimensional copulas," Water Resources Management, vol. 20, no. 5, pp. 795-815, 2006.

[37] J. T. Shiau, S. Feng, and S. Nadarajah, "Assessment of hydrological droughts for the Yellow River, China, using Copulas," Hydrological Processes, vol. 21, no. 16, pp. 2157-2163, 2007.

[38] J. Kwak, D. Kim, S. Kim, V. P. Singh, and H. Kim, "Hydrological Drought Analysis in Namhan River Basin, Korea," Journal of Hydrologic Engineering, vol. 19, no. 8, Article ID 05014001, 2014.

[39] F. Serinaldi, B. Bonaccorso, A. Cancelliere, and S. Grimaldi, "Probabilistic characterization of drought properties through copulas," Physics and Chemistry of the Earth Parts $A / B / C$, vol. 34, no. 10-12, pp. 596-605, 2009.

[40] E. Borgomeo, G. Pflug, J. W. Hall, and S. Hochrainer-Stigler, "Assessing water resource system vulnerability to unprecedented hydrological drought using copulas to characterize drought duration and deficit," Water Resources Research, vol. 51, no. 11, pp. 8927-8948, 2015.

[41] J. T. Shiau and R. Modarres, "Copula-based drought severityduration-frequency analysis in Iran," Meteorological Applications, vol. 16, no. 4, pp. 481-489, 2009.

[42] S. Madadgar and H. Moradkhani, "Drought analysis under climate change using copula," Journal of Hydrologic Engineering, vol. 18, no. 7, pp. 746-759, 2013.

[43] R. Mirabbasi, A. Fakheri-Fard, and Y. Dinpashoh, "Bivariate drought frequency analysis using the copula method," Theoretical and Applied Climatology, vol. 108, no. 1-2, pp. 191-206, 2012.

[44] K. Xu, D. Yang, X. Xu, and H. Lei, "Copula based drought frequency analysis considering the spatio-temporal variability in Southwest China," Journal of Hydrology, vol. 527, pp. 630-640, 2015.

[45] E. J. Burke, S. J. Brown, and N. Christidis, "Modelling the recent evolution of global drought and projections for the twentyfirst century with the Hadley Centre climate model," Journal of Hydrometeorology, vol. 7, no. 5, pp. 1113-1125, 2006. 
[46] F. Mpelasoka, K. Hennessy, R. Jones, and B. Bates, “Comparison of suitable drought indices for climate change impacts assessment over Australia towards resource management," International Journal of Climatology, vol. 28, no. 10, pp. 1283-1292, 2008.

[47] S. Blenkinsop and H. J. Fowler, "Changes in European drought characteristics projected by the PRUDENCE regional climate models," International Journal of Climatology, vol. 27, no. 12, pp. 1595-1610, 2007.

[48] Y. Li, W. Ye, M. Wang, and X. Yan, "Climate change and drought: a risk assessment of crop-yield impacts," Climate Research, vol. 39, pp. 31-46, 2009.

[49] Y. Choi, "Trends on temperature and precipitation extreme events in Korea," Journal of the Korean Geographical Society, vol. 39, pp. 711-721, 2004 (Korean).

[50] J.-W. Lee, S.-Y. Hong, E.-C. Chang, M.-S. Suh, and H.-S. Kang, "Assessment of future climate change over East Asia due to the RCP scenarios downscaled by GRIMs-RMP," Climate Dynamics, vol. 42, no. 3-4, pp. 733-747, 2014.

[51] W.-H. Nam, M. J. Hayes, M. D. Svoboda, T. Tadesse, and D. A. Wilhite, "Drought hazard assessment in the context of climate change for South Korea," Agricultural Water Management, vol. 160, pp. 106-117, 2015.

[52] C. J. Kim, M. J. Park, and J. H. Lee, "Analysis of climate change impacts on the spatial and frequency patterns of drought using a potential drought hazard mapping approach," International Journal of Climatology, vol. 34, no. 1, pp. 61-80, 2014.

[53] J. Xia, L. Ning, Q. Wang, J. Chen, L. Wan, and S. Hong, "Vulnerability of and risk to water resources in arid and semiarid regions of West China under a scenario of climate change," Climatic Change, vol. 1, pp. 15-23, 2016.

[54] L. Wang and W. Chen, "A CMIP5 multimodel projection of future temperature, precipitation, and climatological drought in China," International Journal of Climatology, vol. 34, no. 6, pp. 2059-2078, 2014.

[55] Y. Li, H. Huang, H. Ju et al., "Assessing vulnerability and adaptive capacity to potential drought for winter-wheat under the RCP 8.5 scenario in the Huang-Huai-Hai Plain," Agriculture, Ecosystems \& Environment, vol. 209, pp. 125-131, 2015.

[56] L. Wang, W. Chen, and W. Zhou, "Assessment of future drought in Southwest China based on $\mathrm{CMIP}_{5}$ multimodel projections," Advances in Atmospheric Sciences, vol. 31, no. 5, pp. 1035-1050, 2014.

[57] D. Praveen, A. Ramachandran, R. Jaganathan, E. Krishnaveni, and K. Palanivelu, "Projecting droughts in the purview of climate change under RCP 4.5 for the Coastal Districts of South India," Indian Journal of Science and Technology, vol. 9, no. 6, 2016.

[58] M. Dubrovsky, M. D. Svoboda, M. Trnka et al., "Application of relative drought indices in assessing climate-change impacts on drought conditions in Czechia," Theoretical and Applied Climatology, vol. 96, no. 1-2, pp. 155-171, 2009.

[59] A. K. Mishra and V. P. Singh, "Analysis of drought severity-areafrequency curves using a general circulation model and scenario uncertainty," Journal of Geophysical Research Atmospheres, vol. 114, no. 6, p. 18, 2009.

[60] U. Kim and J. J. Kaluarachchi, "Climate change impacts on water resources in the upper Blue Nile River Basin, Ethiopia," Journal of the American Water Resources Association, vol. 45, no. 6, pp. 1361-1378, 2009.

[61] S. Ghosh and P. P. Mujumdar, "Climate change impact assessment: uncertainty modeling with imprecise probability," Journal of Geophysical Research, vol. 114, no. 18, 2009.
[62] V. Mishra, K. A. Cherkauer, and S. Shukla, "Assessment of drought due to historic climate variability and projected future climate change in the Midwestern United States," Journal of Hydrometeorology, vol. 11, no. 1, pp. 46-68, 2010.

[63] R. M. S. Yu, T. Osborn, D. Conway, R. Warren, and R. Hankin, "European drought under climate change and an assessment of the uncertainties in projections," in Proceedings of the EGU General Assembly 2012, vol. 14, p. 563, Vienna, Austria, April 2012.

[64] A. K. Gobena and T. Y. Gan, "Assessment of trends and possible climate change impacts on summer moisture availability in western canada based on metrics of the palmer drought severity index," Journal of Climate, vol. 26, no. 13, pp. 4583-4595, 2013.

[65] M. A. Asadi Zarch, B. Sivakumar, and A. Sharma, "Droughts in a warming climate: a global assessment of Standardized precipitation index (SPI) and Reconnaissance drought index (RDI)," Journal of Hydrology, vol. 526, pp. 183-195, 2015.

[66] Intergovernmental Panel on Climate Change, IPCC 5th Report, IPCC Press, Geneva, Switzerland, 2014.

[67] U. S. Panu and T. C. Sharma, "Challenges in drought research: some perspectives and future directions," Hydrological Sciences Journal, vol. 47, supplement 1, pp. S19-S30, 2002.

[68] A. Mishra and V. Desai, "Spatial and temporal drought analysis in the Kansabati river basin, India," International Journal of River Basin Management, vol. 3, no. 1, pp. 31-41, 2005.

[69] M. Mirakbari, A. Ganji, and S. R. Fallah, "Regional bivariate frequency analysis of meteorological droughts," Journal of Hydrologic Engineering, vol. 15, no. 12, pp. 985-1000, 2010.

[70] X. Hong, S. Guo, L. Xiong, and Z. Liu, "Spatial and temporal analysis of drought using entropy-based standardized precipitation index: a case study in Poyang Lake basin, China," Theoretical and Applied Climatology, vol. 122, no. 3-4, pp. 543$556,2014$.

[71] X.-F. Liu, S.-X. Wang, Y. Zhou, F.-T. Wang, G. Yang, and W.-L. Liu, "Spatial analysis of meteorological drought return periods in China using copulas," Natural Hazards, vol. 80, no. 1, pp. 367388, 2016.

[72] R. B. Nelsen, An Introduction to Copulas, Springer Series in Statistics, Springer, Berlin, Germany, 2007.

[73] J. C. Rodriguez, "Measuring financial contagion: a copula approach," Journal of Empirical Finance, vol. 14, no. 3, pp. 401423, 2007.

[74] J. S. Ryu, J. Ahn, and S. Kim, "An application of drought severityarea-duration curves using copulas-based joint drought index," Journal of Korea Water Resources Association, vol. 45, no. 10, pp. 1043-1050, 2012.

[75] M. Kyoung, J. Kwak, D. Kim, H. Kim, and V. P. Singh, "Drought analysis based on SPI and SAD curve for the korean peninsula considering climate change," in Climate ChangeGeophysical Foundations and Ecological Effects, J. Blanco, Ed., InTech, London, UK, 2011.

[76] C. Saad, S. El Adlouni, A. St-Hilaire, and P. Gachon, "A nested multivariate copula approach to hydrometeorological simulations of spring floods: the case of the Richelieu River (Québec, Canada) record flood," Stochastic Environmental Research and Risk Assessment, vol. 29, no. 1, pp. 275-294, 2015.

[77] S. E. Adlouni and T. B. M. J. Ouarda, "Joint Bayesian model selection and parameter estimation of the generalized extreme value model with covariates using birth-death Markov chain Monte Carlo," Water Resources Research, vol. 45, no. 6, 2009. 
[78] C.-L. Liu, Q. Zhang, V. P. Singh, and Y. Cui, "Copula-based evaluations of drought variations in Guangdong, South China," Natural Hazards, vol. 59, no. 3, pp. 1533-1546, 2011.

[79] P. Lynch, The Emergence of Numerical Weather Prediction, Cambridge University Press, Cambridge, UK, 2014.

[80] G. A. Meehl, C. Covey, T. Delworth et al., "The WCRP CMIP3 multimodel dataset: a new era in climate change research," Bulletin of the American Meteorological Society, vol. 88, no. 9, pp. 1383-1394, 2007.

[81] J. Sillmann, V. V. Kharin, X. Zhang, F. W. Zwiers, and D. Bronaugh, "Climate extremes indices in the CMIP5 multimodel ensemble: part 1. Model evaluation in the present climate," Journal of Geophysical Research Atmospheres, vol. 118, no. 4, pp. 1716-1733, 2013.

[82] K. E. Trenberth, J. T. Houghton, and L. G. Meira Filho, The Climate System: An Overview, Cambridge University Press, New York, NY, USA, 1996.

[83] "IPCC: table SPM-2, in: summary for Policymakers," in IPCC AR5 WG1, p. 21, 2013.

[84] M. Meinshausen, S. J. Smith, K. Calvin et al., "The RCP greenhouse gas concentrations and their extensions from 1765 to 2300," Climatic Change, vol. 109, no. 1-2, pp. 213-241, 2011.

[85] C. Cho, "Regional climate projection for East Asia and Korea using the HadGEM3-RA," in Proceedings of the 5th Korea-JapanChina Joint Conference on Meteorology, vol. 89, Busan, Republic of Korea, 2011.

[86] Korea Global Atmosphere Watch Center, KGAWC, 2015, https:// www.climate.go.kr.

[87] Water Management Information System (WAMIS, 2016), http:// www.wamis.go.kr.

[88] L. A. Moyé, A. S. Kapadia, I. M. Cech, and R. J. Hardy, “The theory of runs with applications to drought prediction," Journal of Hydrology, vol. 103, no. 1-2, pp. 127-137, 1988. 

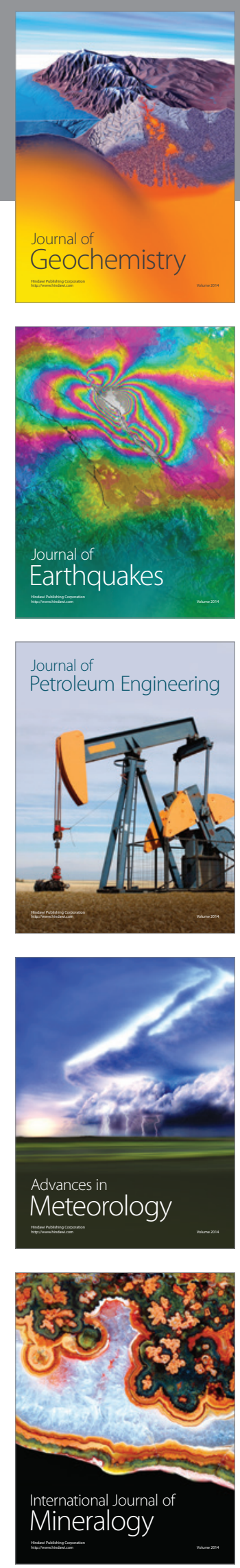
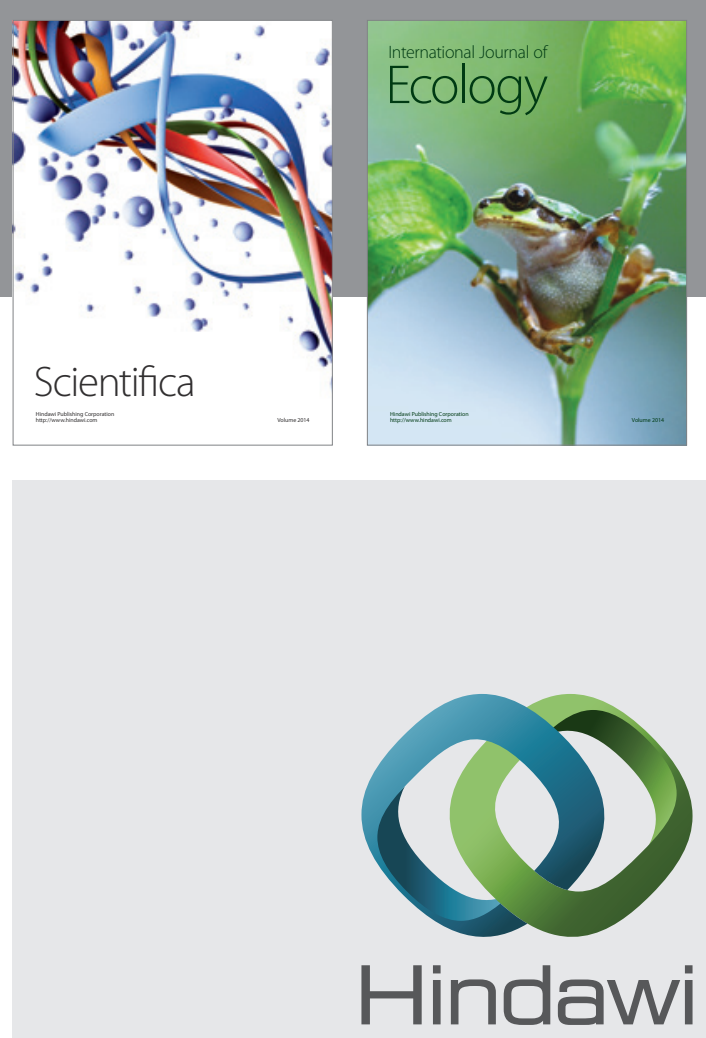

Submit your manuscripts at

http://www.hindawi.com
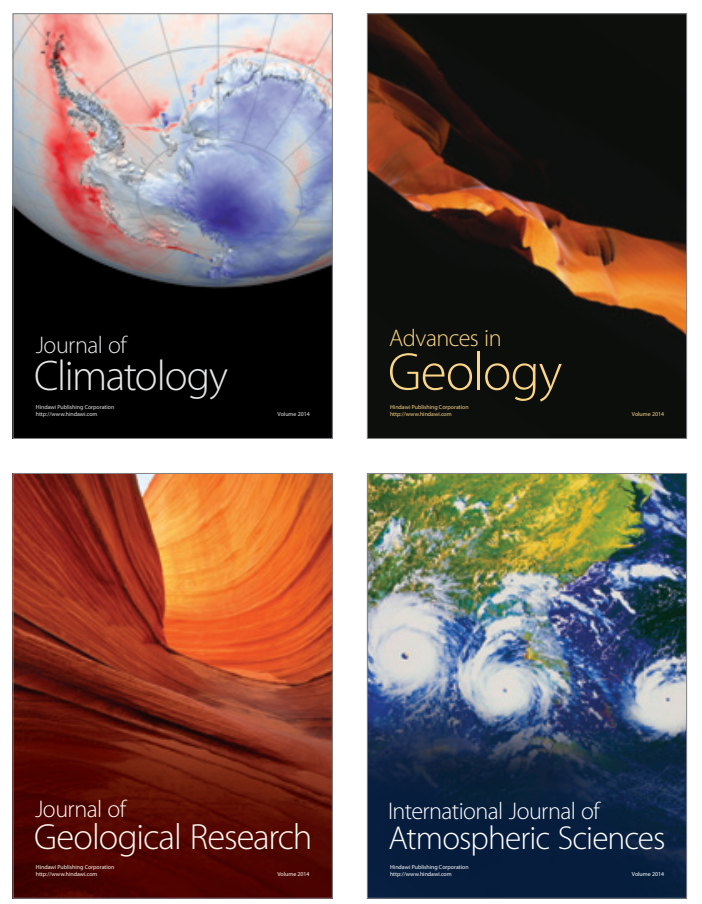

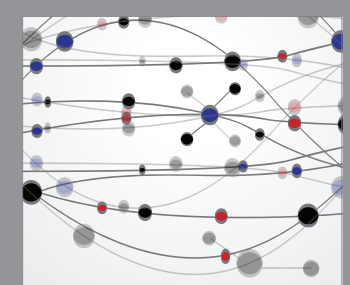

The Scientific

\section{World Journal}
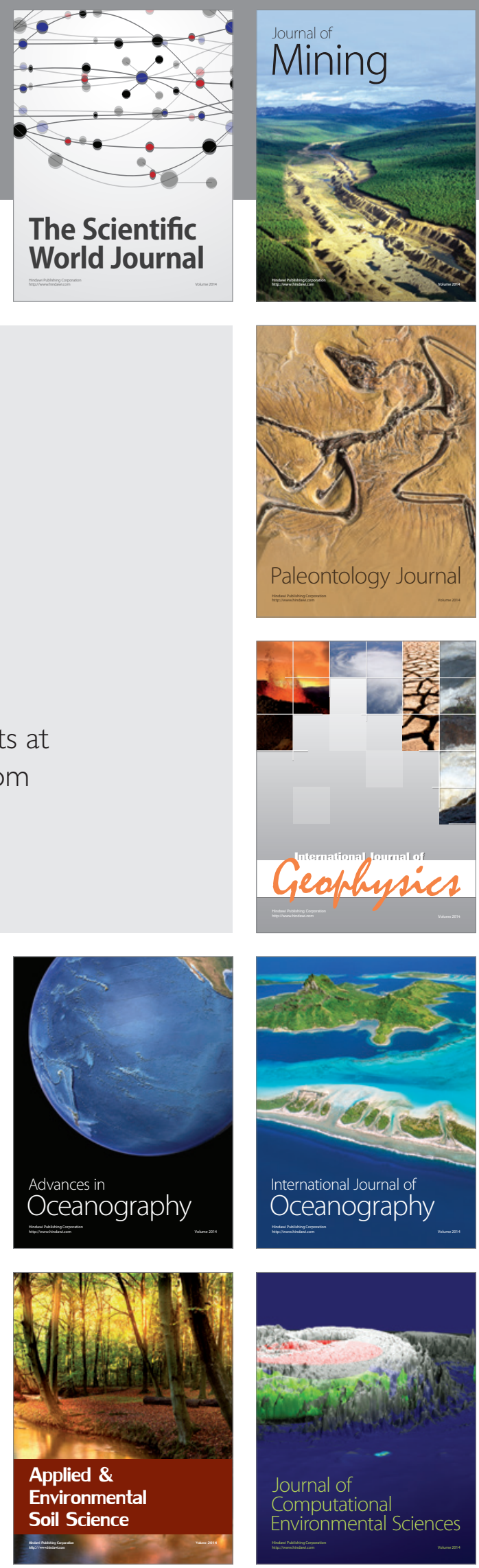